\title{
ADAPTABILIDADE E ESTABILIDADE DE LINHAGENS DE SORGO EM AMBIENTES COM E SEM RESTRIÇÃO HÍDRICA
}

\author{
CÍCERO BESERRA DE MENEZES ${ }^{1}$, ADENILSON DA SILVA RIBEIRO², FLÁVIO DESSAUNE \\ TARDIN ${ }^{1}$, ABNER JOSÉ DE CARVALHO ${ }^{2}$, EDSON ALVES BASTOS ${ }^{3}$, MILTON JOSÉ \\ CARDOSO $^{3}$, ARLEY FIGUEIREDO PORTUGAL ${ }^{1}$, KARLA JORGE DA SILVA ${ }^{4}$, CRISLENE \\ VIEIRA DOS SANTOS ${ }^{4}$ e FLÁVIO HENRIQUE LEAL DE ALMEIDA ${ }^{2}$
}

\author{
${ }^{1}$ Embrapa Milho e Sorgo, Sete Lagoas, MG, Brasil, cicero.menezes@embrapa.br, flavio.tardin@embrapa.br,arley.portugal@ \\ embrapa.br \\ ${ }^{2}$ Unimontes, Janaúba, MG, Brasil, abjocar@yahoo.com.br, adenilsonagro@yahoo.com.br, flavioleal33@hotmail.com \\ ${ }^{3}$ Embrapa Meio-Norte,Teresina, PI, Brasil,edson.bastos@embrapa.br,milton.cardoso@embrapa.br \\ ${ }^{4}$ UFSJ, SeteLagoas, MG, Brasil,karla.js@hotmail.com,cris-vieira15@hotmail.com
}

$$
\overline{\text { Revista Brasileira de Milho e Sorgo, v.14, n.1, p. 101-115, } 2015}
$$

\begin{abstract}
RESUMO - O objetivo do presente trabalho foi selecionar linhagens de sorgo mais tolerantes à seca e responsivas à melhoria do ambiente. Os tratamentos foram arranjados em um esquema fatorial, composto por 25 linhagens e dois regimes hídricos. Os experimentos foram realizados em três anos consecutivos (2006, 2007 e 2008), totalizando seis experimentos. O delineamento utilizado foi o de blocos casualizados, com três repetições. Para seleção dos genótipos foram estimados parâmetros de adaptabilidade e estabilidade para produtividade de grãos utilizando os métodos univariados de Lin \& Bins e Annicchiarico, e análise multivariada AMMI. A seleção para adaptabilidade geral pelos dois primeiros métodos é bastante similar, diferindo, no entanto do terceiro método. A produtividade média das linhagens no ambiente com estresse foi 39\% menor quando comparado ao ambiente sem estresse hídrico. Foram detectadas diferenças significativas para as interações linhagens (L) x anos (A), linhagens (L) x regime hídrico (R) e LxAxR, indicando a complexidade de se trabalhar com seleção para tolerância a seca em sorgo em nível de campo. Os métodos univariados complementaram o método AMMI, possibilitando a seleção de linhagens tolerantes, estáveis e responsivas ao ambiente. As linhagens mais tolerantes e estáveis foram 9929020, CMSXS 230B e N 95B, seguidas pelas linhagens BR 008B, Tx 2737 e Tx 2908, de produtividades elevadas, mas de estabilidades intermediárias.
\end{abstract} Palavras-chave: Sorghum bicolor; estresse hídrico; estresse abiótico; tolerância à seca; melhoramento vegetal.

\section{ADAPTABILITY AND STABILITY OF SORGHUM GENOTYPES CULTIVATED UNDER WATER STRESS AND FULL IRRIGATION}

\begin{abstract}
The objective of this work was to identify sorghum lines tolerant to water stress at post-flowering. The treatments were set as a factorial arrangement, comprised of two water regimes and 25 genotypes, during the years of 2006, 2007 and 2008. The experimental design was a randomized block, with three replications. Since the combined analysis of variance revealed significant differences among the lines, among the environments and the presence of significant genotypes x environments interaction, two univariate stability estimates (Lin \& Binns and Annicchiarico) and one multivariate (AMMI) were utilized for ranking the yield stability of the genotypes. Water stress decreases significantly the yield of the genotypes. The two univariate methods presented similar results, and were complementary to AMMI, allowing the selection of tolerant and responsive lines. Lines 9929020, CMSXS 230B and N 95B were drought tolerant and stable, followed by the lines BR 008B, Tx 2737 e Tx 2908 with high yield, but intermediate stability.
\end{abstract}

Key words: Sorghum bicolor; water stress; abiotic stress; drought tolerance; plant breeding. 
A produção brasileira de grãos depende, na sua maior parte, da precipitação pluviométrica, o que faz com que, em regiões de baixa ocorrência de chuvas ou irregularidade de sua distribuição, normalmente haja redução na produção de grãos. Dessa maneira, a seleção de genótipos mais adaptados a condições de estresse hídrico pode contribuir para aumentar a viabilidade do cultivo agrícola em regiões com limitações de água ao longo do ano, como nas regiões de clima semiárido, ou no centro oeste e sudeste em períodos de segunda safra.

O sorgo é um dos cereais mais tolerantes à seca, mas o estresse hídrico acentuado pode causar danos em todas as fases do desenvolvimento da planta. Todavia a fase reprodutiva é aquela em que o estresse hídrico proporciona maior perda de produtividade de grãos (Lima, 2011; Schaffert at al, 2011). Nessa fase, a falta de água provoca redução na formação dos grãos, seja pelo abortamento ou pelo desenvolvimento insuficiente da panícula e, mesmo após a fertilização do óvulo, o grão tem seu enchimento prejudicado (Magalhães et al., 2003). Esse problema é agravado nas condições da safrinha em que é mais frequente a ocorrência de períodos prolongados sem chuvas. Assim, torna-se imprescindível a disponibilidade de genótipos de sorgo tolerantes ao estresse hídrico, principalmente no período de pós-florescimento.

A interação entre genótipos e ambientes (GxA) assume papel importante na manifestação fenotípica do caráter tolerância a seca. Esta interação pode ser contornada, pela identificação de cultivares específicas para cada ambiente, o que é praticamente inexequível, pois se torna dispendiosa para instituições de pesquisa e qualquer variação imprevista no ambiente específico pode fazer com que tais cultivares não se mostrem mais adaptadas. Outra opção mais viável neste caso é a identificação de linhagens com maior estabilidade fenotípica e responsiva à melhoria do ambiente.

Vários métodos, baseados em diferentes princípios, foram descritos para avaliação da interação GxA e para a determinação da adaptabilidade e da estabilidade fenotípica. Os métodos de Lin \& Binns (1988) e Annicchiarico (1992) são altamente correlacionados e possibilitam interpretação fácil, baseada na análise de apenas um parâmetro. Outro método de aplicação mais recente, que também permite inferências dessa natureza, é a chamada análise AMMI (Additive Main Effects and Multiplicative Interaction Analysis), que é traduzida por análise de efeitos principais aditivos e interação multiplicativa. Este método combina técnicas estatísticas, como a análise de variância e a análise de componentes principais, para ajustar, respectivamente, os efeitos principais (genótipos e ambientes) e os efeitos da interação GxA (Duarte \&Vencovsky, 1999; Ramalho et al., 2012).

Diante do exposto, o objetivo deste trabalho foi selecionar linhagens de sorgo mais tolerantes à seca e responsivas à melhoria do ambiente, para utilização como parentais de híbridos e introdução em população para seleção recorrente, no programa de melhoramento de sorgo granífero.

\section{Material e Métodos}

Os ensaios foram instalados sob sistema convencional de cultivo na Fazenda Experimental do Gorutuba, pertencente à Embrapa Milho e Sorgo, localizada no município de Nova Porteirinha, MG, com coordenadas geográficas $43,3^{\circ} \mathrm{O}$ e $15,8^{\circ} \mathrm{S}$. O clima, segundo Köppen (1948), é do tipo AW (tropical chuvoso, savana com inverno seco). O solo utilizado foi classificado como latossolo vermelho-amarelo de textura média. Os dados meteorológicos de temperatura 
e precipitação na época da experimentação podem ser observados na Figura 1. Os ensaios de tolerância à seca, em nível de campo, são realizados no Norte de Minas Gerais, por ser este um local com estação seca mais definida do que no Centro Oeste ou Sudeste. As linhagens selecionadas serão utilizadas para produção de híbridos visando resistência ao estresse hídrico da safrinha tardia nas principais regiões produtoras de sorgo.

Os tratamentos foram dispostos em blocos ao acaso, com três repetições e esquema fatorial $25 \mathrm{x}$ 2 , envolvendo 25 linhagens de sorgo e dois regimes hídricos (com e sem restrição hídrica), durante os anos de 2006, 2007 e 2008, totalizando seis experimentos. As linhagens utilizadas no trabalho pertencem ao programa de melhoramento de sorgo da Embrapa Milho e Sorgo, e compreendem 17 linhagens restauradoras da fertilidade e 8 linhagens mantenedoras, algumas das quais são parentais de híbridos comerciais.
No ambiente sem restrição hídrica, os genótipos foram submetidos a uma condição de cultivo irrigado até a maturação fisiológica dos grãos. No ambiente com restrição hídrica cessou-se a irrigação na fase de emborrachamento da planta, aproximadamente em torno de 45 dias após plantio. No primeiro ano (2006) a irrigação foi cortada mais no final do emborrachamento. Baseado na redução da produtividade de 2006, comparando-se os ambientes com e sem estresse, optou-se por cortar mais cedo a irrigação em 2007 e 2008, para aumentar o estresse hídrico.

Os ensaios foram implantados sempre entre os meses de junho e julho de cada ano, para que coincidisse com o período de seca característico da região. As parcelas experimentais foram constituídas por quatro fileiras de $5 \mathrm{~m}$ de comprimento, espaçadas de $0,5 \mathrm{~m}$, sendo que apenas as duas fileiras centrais foram consideradas como parcela útil.



FIGURA 1. Dados médios de temperatura, em graus Celsius $\left({ }^{\circ} \mathrm{C}\right)$, e precipitação pluvial, em milímetros $(\mathrm{mm})$, obtidos na Estação Climatológica da EPAMIG, Nova Porteirinha,MG, para os anos de 2006/2007/2008. 
O plantio foi realizado manualmente, distribuindo-se cerca de quinze sementes por metro. Quando as plantas atingiram o estádio de três folhas totalmente desenvolvidas, foi realizado um desbaste, ajustando-se a população para aproximadamente 180.000 plantas ha ${ }^{-1}$.

As adubações de plantio e cobertura foram baseadas nas recomendações oficiais para o Estado de Minas Gerais (Alves et al., 1999), considerando-se uma expectativa de produtividade acima de oito $\mathrm{tha}^{-1}$ de grãos. Foram aplicados $250 \mathrm{~kg} \mathrm{ha}^{-1}$ da formulação NPK 08-28-16 no plantio, mais $100 \mathrm{~kg} \mathrm{ha}^{-1}$ de ureia em cobertura, quando as plantas estavam com 4-5 folhas totalmente expandidas.

O manejo das plantas daninhas foi realizado quimicamente com aplicação dirigida do herbicida Atrazina na dosagem de 31 ha $^{-1}$, seguida de uma capina manual para manter o campo experimental limpo. Para repor a evapotranspiração diária da cultura, foi realizada uma irrigação por semana, utilizando-se o sistema convencional por aspersão, constituído por linhas laterais móveis.

Os cultivos foram permanentemente monitorados e todas as medidas de controle fitossanitário, incluindo o controle de formigas e ataque de pássaros, foram tomadas conforme a necessidade.

A colheita foi realizada na última semana de outubro, quando as plantas se encontravam no final da maturação fisiológica, caracterizada pela maturação dos grãos. Para a colheita das panículas de cada parcela, foram utilizadas tesouras de poda e as panículas foram acondicionadas em sacos de ráfia e transportadas para o galpão de melhoramento de sorgo na unidade da Embrapa Milho e Sorgo em Sete Lagoas, MG, onde se procederam a trilha e pesagem dos grãos das parcelas, calculando-se a produtividade de grãos, em $\mathrm{t} \mathrm{ha}^{-1}$, corrigida para $13 \%$ de umidade.
Os dados obtidos foram submetidos à análise de variância individual para cada regime hídrico, em cada ano agrícola, para determinação da variância residual e teste de homogeneidade dessas variâncias. Após comprovação da homogeneidade das variâncias procedeu-se a análise conjunta, envolvendo os seis experimentos.

A adaptabilidade e estabilidade da produtividade de grãos foi analisada utilizando-se os métodos de Lin \& Binns (1988), Annicchiarico (1992) e AMMI (Zobel et al., 1988), empregando-se o software Estabilidade, desenvolvido por Ferreira (2014). As metodologias de Lin \& Binns (1988) e Annicchiarico (1992) classificam os ambientes como favoráveis e desfavoráveis com base nas médias das cultivares. O AMMI associa um modelo aditivo e multiplicativo para explicar a interação genótipos e ambientes. Este método integra a análise de variância e a técnica estatística multivariada denominada de análise de componentes principais. O modelo utilizado envolve os efeitos aditivos dos genótipos e ambientes (efeitos principais) e multiplicativo da interação genótipos $\mathrm{x}$ ambientes.

\section{Resultados e Discussão}

A relação do maior e menor quadrado médio do resíduo dos seis experimentos foi de 3,05. Portanto as variâncias individuais foram homogêneas e a análise conjunta pôde ser realizada. A média geral de produtividade de grãos das linhagens foi de 4,8 t ha ${ }^{-1}$ (Tabela 1), situando-se acima da média nacional de híbridos comerciais plantados, que é de $2,7 \mathrm{t}$ ha $^{-1}$ (CONAB, 2013), dado este que denota o elevado potencial produtivo destas linhagens. $\mathrm{O}$ coeficiente de variação experimental foi de $21,9 \%$, podendo ser considerado intermediário, mas compatível com 
aqueles verificados para produtividade, geralmente de natureza genética complexa e muito influenciada pelo ambiente de cultivo.

O estresse hídrico reduziu significativamente a produtividade das linhagens em 39\%, considerando as médias dos três anos $\left(5.97 \mathrm{t} \mathrm{ha}^{-1}\right.$ sem estresse e $3.63 \mathrm{t} \mathrm{ha}^{-1}$ com estresse), constatando que o estresse hídrico pode ser um fator limitante para produção de sorgo em áreas ou épocas de baixa pluviosidade (Tabela 2). Para trabalhos de tolerância a seca, recomenda-se estresses hídricos que reduzam a produtividade acima de $30 \%$, de forma a melhor discriminar os genótipos tolerantes dos suscetíveis. A redução obtida no presente trabalho está próximo ao encontrado por outros autores, como Albuquerque et al (2011), avaliando linhagens, e Tardin et al. (2013), avaliando híbridos, que encontraram reduções de 45 e $54 \%$ respectivamente.

As reduções observadas nos anos de 2007 (43\%) e 2008 (57\%) foram maiores que a redução de
2006 (20\%), devido ao estresse hídrico mais severo aplicado (Tabela 2). O corte da irrigação nos anos de 2007 e 2008 ocorreu uma semana antes do realizado em 2006, com objetivo de provocar maior estresse hídrico e aumentar a precisão na seleção daquelas linhagens mais tolerantes. As temperaturas foram muito similares entre os anos agrícolas e só houve incidência de chuva durante os experimentos de 2006 (Figura 1), o que ajuda a explicar a menor redução de produtividade de grãos neste ano.

Pelos resultados da pesquisa fica clara a importância do desenvolvimento de linhagens de sorgo mais tolerantes à seca para dar suporte à expansão da cultura, não só em região semiárida do Nordeste, mas também na segunda safra no Centro Oeste e Sudeste. Mais de $90 \%$ do sorgo granífero é plantado na safrinha, como sucessão à soja de verão. A janela de plantio de sorgo safrinha é muito curta, indo de meados de fevereiro a meados de março nas principais regiões de plantio. Quando semeado dentro desta faixa

TABELA 1. Análise de variância da produtividade de grãos, de 25 linhagens de sorgo, avaliadas em condições de presença e ausência de estresse hídrico, durante três anos consecutivos. Sete Lagoas, 2014.

\begin{tabular}{lcccc}
\hline FV & GL & QM & F & $\mathrm{R}^{2}$ \\
\hline (B/L)/A & 12 & 6,3858 & & \\
Cultivares (C) & 24 & 9,4067 & $8,53^{* *}$ & $18,26^{* *}$ \\
Anos (A) & 2 & 116,6077 & $96,58^{* *}$ & \\
Regime Hídrico (R) & 1 & 616,7597 & $2,21^{* *}$ & 45,06 \\
C x A & 48 & 2,4346 & $2,29^{* *}$ & 23,41 \\
C x R & 24 & 2,5294 & $5,44^{*}$ & 31,53 \\
A x R & 2 & 34,7578 & $1,54^{*}$ & \\
C x A x R & 48 & 1,7034 & & \\
Resíduo & 288 & 1,1034 & \\
\hline Média & 4.80 & & \\
CV (\%) & 21,90 & & \\
$\mathrm{~h}^{2}$ média (\%) & 88,27 & & \\
${ }^{* *},{ }^{*}$ Significativo em níveis de 1 e 5\% de probabilidade, respectivamente. & \\
\hline
\end{tabular}




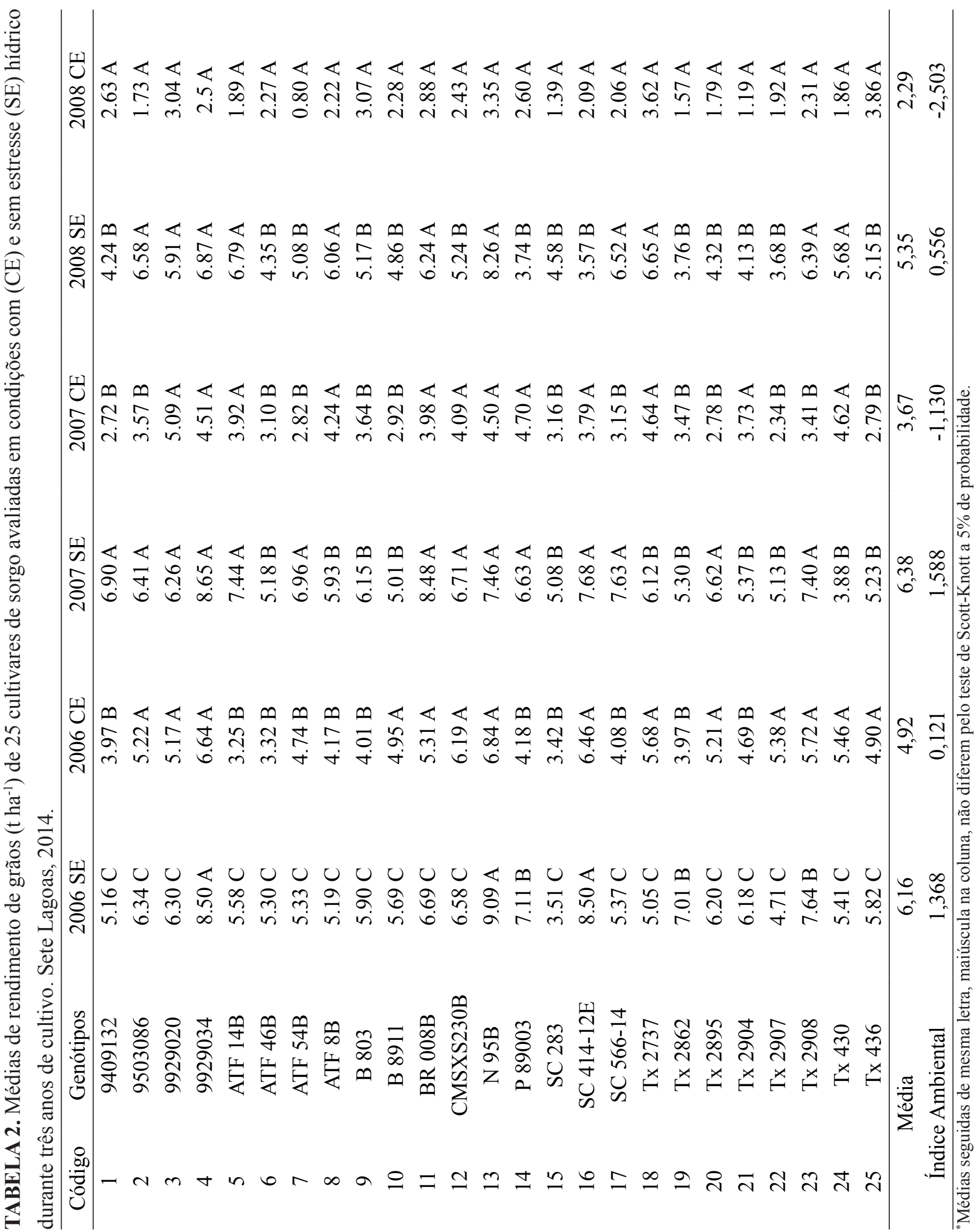


o sorgo ainda terá chuvas até o seu florescimento, que ocorrerá em maio. No entanto, qualquer atraso na colheita da soja, leva o plantio do sorgo para o final de março, aumentando o risco de perdas de produtividade, pois plantios a partir desta data têm grande possibilidade de sofrer estresse hídrico após o florescimento da cultura. O plantio tardio do sorgo após fevereiro têm sido um dos principais fatores de baixa produtividade da cultura.

Considerando o teste de agrupamento de médias (Tabela 2), somente as linhagens 9929034 e N 95B foram classificadas no grupo das mais produtivas em todos os ambientes. A produtividade das demais linhagens foi muito influenciada pelo ambiente, dado também confirmado pela significância das interações.

Foram detectadas diferenças significativas para as interações linhagens (L) $x$ anos (A), linhagens (L) x regime hídrico (R) e LxAxR (Tabela 1), indicando a complexidade de se trabalhar com seleção para tolerância a seca em condições de campo. O comportamento diferencial de linhagens, ante as variações de anos e regimes hídricos, é de grande interesse para o melhoramento, pois é determinante na indicação das linhagens para as diferentes regiões produtoras. Verifica-se que a interação das linhagens com anos foi mais pronunciada $\left(\mathrm{R}^{2}=45,06 \%\right)$ do que aquela com regimes hídricos $\left(\mathrm{R}^{2}=23,41 \%\right)$, devendo, portanto preocupar-se em identificar, entre as linhagens disponíveis, aquelas que apresentam boa produtividade e sem grandes oscilações, de tal forma que o desempenho obtido não seja afetado de um ano agrícola para outro. Para tanto se faz necessário aumentar o número de anos nas avaliações de seleção para tolerância à seca em sorgo. Estudos mostram interações complexas genótipos $\mathrm{x}$ ambientes e genótipos $\mathrm{x}$ anos até mesmo dentro da mesma região produtora de sorgo (Oliveira et al., 2002; Silva et al., 2009; Almeida Filho at al., 2010).

A variação de produtividade verificada entre ambientes (Tabela 2) evidencia a instabilidade nas condições climáticas durante o período estudado. $\mathrm{O}$ índice ambiental é a diferença entre a média geral do ambiente e a média geral de todos os ambientes, classificando o ambiente como favorável quando o índice é positivo e desfavorável quando o índice é negativo. Os ambientes 2006 com e sem estresse, 2007 e 2008, ambos sem estresse foram classificados como ambientes favoráveis, ao passo que 2007 e 2008 com estresse foram classificados como ambientes desfavoráveis (Tabela 2). O fator que mais contribuiu para o desfavorecimento dos ambientes foi o regime hídrico, pois em 2006 quando o estresse foi menor, ambos ambientes foram considerados favoráveis.

Na Tabela 3 estão apresentados os parâmetros de adaptabilidade e estabilidade (Pi) utilizando o método de Lin \& Binns (1988). Esse parâmetro indica o quanto a linhagem está próxima do desempenho ideal, referenciado como sendo a da linhagem com a maior produtividade em cada ambiente estudado (Cruz et al., 2014). As linhagens mais estáveis, considerando a média de todos os ensaios (menor Pig), foram N95 B, 9929034, BR 008B, 9929020, CMSXS 230B, Tx 2908, 9503086, Tx 2737, SC 414-12E e SC566-14 (Tabela 3). As cinco primeiras linhagens também foram estáveis considerando somente os ambientes favoráveis (menores Pifav) e somente os ambientes desfavoráveis (menores Pidesfav). Linhagens estáveis ao longo dos anos e ambientes são preferidas, pois apresentam produtividades previsíveis, o que facilita a indicação destas para utilização em programa de melhoramento na produção de híbridos ou criação de populações para extração de linhagens. Verificouse ainda, linhagem que apresenta adaptabilidade 
específica, como 9503086, estável nos ambientes favoráveis e baixa estabilidade para ambientes com déficit hídrico (Tabela 3). Ao contrário, a linhagem $\mathrm{P}$ 89003 foi estável nos ambientes desfavoráveis e teve baixa estabilidade nos ambientes favoráveis, sendo linhagem não responsiva à melhoria do ambiente. A linhagem Tx 2737 foi estável nos ambientes desfavoráveis e de estabilidade intermediária nos ambientes favoráveis. As linhagens Tx 2862, Tx 2907 e SC 283 foram as menos estáveis em todos os ambientes, tanto favoráveis quanto desfavoráveis.

No método proposto por Annicchiarico, a estabilidade é medida pela superioridade do genótipo em relação à média de cada ambiente. $\mathrm{O}$ método baseia-se na estimação de um índice de confiança de um determinado genótipo mostrar comportamento relativamente superior. Com base no índice de confiança ou de recomendação, podem-se indicar as linhagens: N 95B, 9929034, BR 008B, 9929020, CMSXS 230B, Tx 2737, Tx 2908, SC414-12E, P 89003 e 9503086 , considerando a sua produtividade em todos os ambientes, ou seja, adaptabilidade geral (Tabela 3). Nos ambientes classificados como favoráveis as linhagens N95B, 9929034, Tx 2908, BR 008, CMSXS 230B, 9503086, SC414-12E, 9929020, Tx 2737 e SC566-14 foram mais estáveis e com probabilidade de apresentar produtividade superior à média de cada ambiente. Nos ambientes classificados como desfavoráveis destacaram-se as linhagens Tx 2737, 9929020, N 95B, P 89003, BR 008B, 9929034, B 803, CMSXS 230B, Tx 436 e ATF 8B (Tabela 3). Novamente as linhagens Tx2862, Tx2907 e SC283 foram menos estáveis tanto nos ambientes favoráveis quanto nos desfavoráveis.

O desdobramento da interação linhagens (L) $\mathrm{x}$ ambientes (E) foi significativo para os modelos AMMI1, AMMI2, AMMI3 e não significativo para os desvios (Tabela 4). Isso significa que os três primeiros componentes (IPCA1, IPCA2 e IPCA3) capturaram a maior parte da variação da interação. O primeiro componente principal (IPCA1) explicou $36,96 \%$ e o segundo (IPCA2) explicou $27,28 \%$. Os dois eixos, portanto, explicaram $64,24 \%$ da Soma de Quadrados da interação L x E (Tabela 4). Este resultado está próximo ao encontrado por outros autores que trabalharam com produtividade em sorgo. Adugna (2008), avaliando quinze genótipos em oito ambientes, observou que o modelo AMMI2 explicou 68,7\% da variabilidade devido à interação. Almeida Filho et al. (2010) estudaram 25 híbridos de sorgo granífero em sete ambientes e encontrou que os dois primeiros componentes principais explicaram $67,25 \%$ da soma de quadrado da interação. Em ambos os trabalhos os autores conseguiram selecionar com segurança genótipos adaptados baseados na análise AMMI.

$\mathrm{Na}$ representação gráfica da produtividade das linhagens e ambientes versus os escores correspondentes do primeiro componente da análise AMMI (Figura 2), as linhagens plotadas próximas da reta paralela ao eixo das abscissas que cruza o escore zero, ou seja, escore próximo de zero, contribuem menos para a interação. As linhagens 1 (9409132), 2 (9503086), 6 (ATF46B), 7 (ATF54B), 10 (B 8911), 11 (BR008B), 13 (N95B) e 22 (Tx 2907) foram as mais estáveis contribuindo pouco para a interação. Entre elas, as linhagens 11 (BR008B) e 13 (N 95B) foram as que apresentaram as maiores médias de produtividade. Os ambientes A2 (NP2006 CE), A3 (NP2007 SE) e A4 (NP2007 CE) foram os que menos contribuíram para a interação, ao contrário dos ambientes A1 (NP2006 SE), A5 (NP2008 SE) e A6 (NP2008 CE). A estabilidade ambiental informa sobre a confiabilidade no ordenamento das linhagens num dado ambiente de teste, em relação à classificação para a média de todos os ambientes. Nos ambientes mais estáveis, a classificação 
TABELA 3. Parâmetros de estabilidade e adaptabilidade de linhagens de sorgo, com base nos métodos de Lin \& Binns (1988) e Annicchiarico (1992), para produtividade de grãos de sorgo em condições com e sem estresse hídrico. Sete Lagoas, 2014.

\begin{tabular}{|c|c|c|c|c|c|}
\hline \multicolumn{6}{|c|}{ Lin \& Binns } \\
\hline Linhagens & Pig $^{1}$ & Linhagens & Pifav & Linhagens & Pidesfav \\
\hline N 95B & 0,17 & N 95B & 0,18 & Tx 2737 & 0,07 \\
\hline 9929034 & 0,38 & 9929034 & 0,29 & N 95B & 0,15 \\
\hline Tх 2908 & 1,14 & Tх 2908 & 1,05 & 9929020 & 0,17 \\
\hline BR 008B & 1,20 & BR 008B & 1,52 & Р 89003 & 0,43 \\
\hline 9929020 & 1,87 & 9503086 & 2,25 & 9929034 & 0,55 \\
\hline CMSXS230B & 1,89 & CMSXS230B & 2,45 & BR 008B & 0,55 \\
\hline 9503086 & 2,07 & 9929020 & 2,72 & В 803 & 0,69 \\
\hline Tx 2737 & 2,24 & $\mathrm{SC} 414-12 \mathrm{E}$ & 2,93 & CMSXS230B & 0,76 \\
\hline SC 414-12E & 2,36 & SC566-14 & 3,18 & ATF 8B & 0,85 \\
\hline SC566-14 & 2,71 & Tx 2737 & 3,33 & Tx 430 & 1,06 \\
\hline ATF 14B & 2,84 & ATF 14B & 3,61 & SC 414-12E & 1,21 \\
\hline В 803 & 3,06 & Tx 2895 & 3,83 & ATF 14B & 1,31 \\
\hline Р 89003 & 3,10 & ATF 54B & 3,94 & Tx 2908 & 1,31 \\
\hline ATF 8B & 3,16 & В 803 & 4,25 & Tx 436 & 1,33 \\
\hline Tx 2895 & 3,36 & ATF 8B & 4,32 & ATF 46B & 1,62 \\
\hline Tx 436 & 3,43 & P 89003 & 4,44 & 9503086 & 1,72 \\
\hline ATF 54B & 3,84 & Tx 436 & 4,48 & SC566-14 & 1,75 \\
\hline B 8911 & 3,93 & B 8911 & 4,99 & 9409132 & 1,79 \\
\hline Tx 430 & 4,08 & Tx 2904 & 5,10 & B 8911 & 1,80 \\
\hline Tx 2904 & 4,15 & 9409132 & 5,36 & Tx 2862 & 1,98 \\
\hline 9409132 & 4,17 & Tx 2862 & 5,51 & Tx 2904 & 2,25 \\
\hline Tx 2862 & 4,33 & Tx 430 & 5,60 & Tx 2895 & 2,41 \\
\hline ATF 46B & 5,05 & ATF 46B & 6,76 & SC 283 & 2,46 \\
\hline Tx 2907 & 5,50 & Tx 2907 & 6,83 & Tx 2907 & 2,84 \\
\hline SC 283 & 6,57 & SC 283 & 8,63 & ATF 54B & 3,63 \\
\hline
\end{tabular}


Annicchiarico

\begin{tabular}{cccccc}
\hline Linhagens & Wi & Linhagens & Wi (f) & Linhagens & Wi(d) \\
\hline N 95B & 133,71 & N 95B & 134,96 & Tx 2737 & 136,18 \\
9929034 & 125,16 & 9929034 & 133,03 & 9929020 & 134,47 \\
BR 008B & 113,79 & Tx 2908 & 117,90 & N 95B & 129,96 \\
9929020 & 109,92 & BR 008B & 113,30 & P 89003 & 117,94 \\
Tx 2737 & 109,74 & CMSXS230B & 105,59 & BR 008B & 113,75 \\
Tx 2908 & 108,23 & 9503086 & 105,30 & 9929034 & 113,34 \\
CMSXS 230B & 106,25 & SC 414-12E & 105,20 & B 803 & 109,84 \\
SC 414-12E & 101,06 & 9929020 & 102,56 & CMSXS 230B & 107,74 \\
P 89003 & 96,72 & Tx 2737 & 99,13 & Tx 436 & 104,25 \\
9503086 & 96,6 & SC566-14 & 97,20 & ATF 8B & 102,67 \\
B 803 & 95,75 & Tx 2895 & 94,58 & Tx 2908 & 95,26 \\
ATF 8B & 94,21 & ATF 54B & 94,12 & Tx 430 & 94,80 \\
Tx 436 & 93,60 & ATF 14B & 92,47 & SC 414-12E & 94,72 \\
SC566-14 & 93,00 & Tx 436 & 90,92 & ATF 14B & 89,98 \\
ATF 14B & 91,99 & B 803 & 90,53 & ATF 46B & 89,02 \\
Tx 430 & 89,05 & ATF 8B & 90,07 & SC566-14 & 87,12 \\
B 8911 & 87,62 & B 8911 & 88,04 & 9409132 & 86,62 \\
Tx 2895 & 86,97 & P 89003 & 88,01 & B 8911 & 85,71 \\
9409132 & 85,46 & Tx 2904 & 86,40 & 9503086 & 82,01 \\
ATF 46B & 80,48 & Tx 430 & 85,24 & Tx 2895 & 76,45 \\
Tx 2862 & 80,45 & 9409132 & 84,19 & Tx 2862 & 76,35 \\
Tx 2904 & 79,93 & Tx 2862 & 81,79 & Tx 2907 & 69,87 \\
Tx 2907 & 76,01 & Tx 2907 & 78,86 & SC 283 & 68,51 \\
ATF 54B & 75,99 & ATF 46B & 76,79 & Tx 2904 & 67,09 \\
SC 283 & 69,63 & SC 283 & 69,48 & ATF 54B & 47,78 \\
\hline
\end{tabular}

'Pig = Índice de estabilidade geral; Pifav = Índice de estabilidade em ambientes favoráveis; Pidesfav = Índice de estabilidade em ambientes desfavoráveis; $\mathrm{Wi}$ = Índice de confiança geral; Wi(f) = Índice de confiança em ambientes favoráveis e Wi(d) = Índice de confiança em ambientes desfavoráveis. 
das linhagens apresenta maior concordância em relação à média geral dos locais, produzindo ordenamento mais consistente e confiável para fins de seleção.

Pelo modelo AMMI2 temos um biplot em que plotam-se os escores do primeiro componente versus os escores do segundo componente, relativos às linhagens e ambientes. Linhagens e ambientes posicionados próximos à origem dos eixos $(0,0)$ contribuem pouco para a interação total, em relação àqueles mais afastados da origem, e podem ser considerados mais estáveis. É o caso das linhagens 1 (9402132), 2 (9503086), 3 (9929020), 6 (ATF 46B), 9 (B 803), 12 (CMSXS 230B), 13 (N 95B), 21 (Tx 2904), 23 (Tx 2908) e dos ambientes A2 (NP2006CE), A4 (NP2007CE) e A6 (NP2008CE) (Figura 3). As linhagens N 95B, 9928020, CMSXS 230B, 9503068 e o ambiente NP2006CE apresentaram produtividades acima da média geral.

Pelos gráficos é possível também diagnosticar as interações específicas entre linhagens e ambientes, observando quais combinações linhagens e ambientes exibem interação negativa e positiva. Neste caso, basta que os pontos referentes à linhagem e ao ambiente estejam afastados da origem (escores com sinais contrários) ou próximos (escore com sinais iguais). A linhagem 16 (SC 414-12) apresentou adaptação específica ao ambiente A1 (NP2006 SE). O mesmo aconteceu com a linhagem 24 (Tx 430) e os ambientes A4 (NP2007 CE) e A6 (NP2008 CE) (Figura 3).

Ao comparar as linhagens mais estáveis pelo método AMMI com as linhagens com adaptabilidade geral pelos métodos de Lin \& Binns e Annicchiarico, apenas as linhagens 2 (9503086), 3 (9929020), 12 (CMSXS 230B), 13 (N 95B) e 23 (Tx 2908) foram selecionadas por todos os métodos. As linhagens 4 (9929034) e 11 (BR 008B) foram estáveis pelos métodos univariados, e de estabilidade intermediária pelo método multivariado. Por outro lado a linhagem 1 (9409132) apresentou alta estabilidade pelo método AMMI e mostrou-se não estável pelos métodos univariados. Os métodos de Lin \& Binns e Annicchiarico

TABELA 4. Análise de variância conjunta para produtividade $\left(\mathrm{t} \mathrm{ha} \mathrm{H}^{-1}\right)$ com desdobramento da interação genótipos $\mathrm{x}$ ambientes (GxA) pelo método AMMI, com respectivas proporções da soma de quadrados da interação GxA acumulada nos três primeiros componentes da análise AMMI, de vinte e cinco linhagens de sorgo em ambientes com e sem restrição hídrica. Sete Lagoas, 2014.

\begin{tabular}{lccccc}
\hline \multicolumn{1}{c}{ FV } & GL & QM & $\mathrm{Fc}^{1}$ & $\mathrm{Pr}>\mathrm{Fc}$ & P.A. $(\%)^{2}$ \\
\hline Linhagens (C) & 24 & 9,4067 & 8,5252 & 0,0000 & \\
Ambientes (E) & 5 & 183,8546 & 166,6262 & 0,0000 & \\
C x E & 120 & 2,1592 & 1,9569 & 0,0000 & \\
$\quad$ IPCA1 & 28 & 3,4201 & 3,0996 & 0,0000 & 36,96 \\
$\quad$ IPCA2 & 26 & 2,7191 & 2,4643 & 0,0001 & 64,24 \\
$\quad$ IPCA3 & 24 & 1,7556 & 1,5911 & 0,0417 & 80,51 \\
Desvios & 42 & 1,2027 & 1,0900 & 0,3334 & 100,00 \\
Resíduo & 288 & 1,1034 & & & \\
\hline
\end{tabular}

${ }^{1}$ Teste Fr de Cornelius et al. (1992); ${ }^{2}$ Proporção da soma de quadrados da interação GxA acumulada em cada componente principal de interação da análise AMMI. 
foram bastante similares, diferindo apenas em uma linhagem. A linhagem SC566-14 foi estável pelo primeiro método e não estável pelo segundo, o contrário do que aconteceu com a linhagem P 89003.

A baixa correlação entre os métodos uni e multivaridos em sorgo, também foi encontrada por Adugna (2008), que avaliou quinze genótipos em oito ambientes, sendo a principal variação dos ambientes atribuída à pluviosidade. Devido à natureza multivariada da interação $\mathrm{G}$ x A, os autores optaram por utilizar o AMMI para a seleção daqueles genótipos mais estáveis.
A escolha da cultivar ideal depende de várias características, sendo que a produtividade assume a maior importância. Assim, quando se trabalha com linhagens, também é imprescindível que aquelas estáveis e adaptadas estejam entre as mais produtivas. Apesar de haver heterose em sorgo para produtividade de grãos, vários trabalhos mostram a superioridade da capacidade geral de combinação em relação à capacidade específica, o que denota a eficiência da seleção per se de linhagens para esta característica (Chalawadi, 2007). Os métodos de Lin \& Binns e Annicchiarico possuem alta correlação com

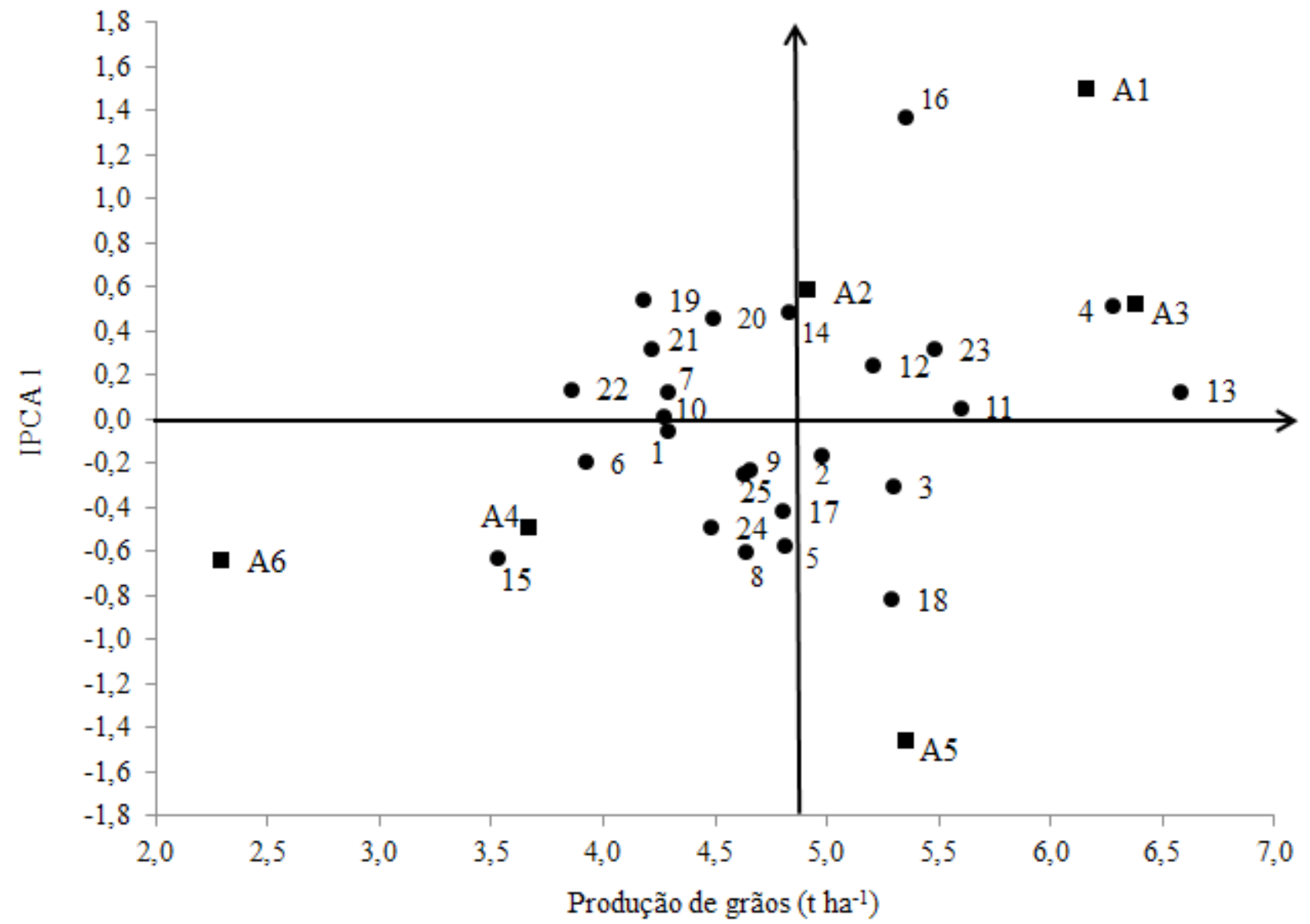

FIGURA 2. Biplot AMMI1 com primeiro componente principal de interação (IPCA1) por produtividade de grãos ( $\mathrm{t}$ ha $\left.{ }^{-1}\right)$ de 25 linhagens de sorgo em seis ambientes. Códigos das linhagens de acordo com Tabela 2. Ambientes A1 (2006 SE), A2 (2006 CE), A3 (2007 SE), A4 (2007 CE), A5 (2008 SE) e A6 (2008 CE). 
produtividade. O método AMMI nem sempre apresenta correlação significativa com a média dos genótipos, o que indica que os genótipos identificados como mais estáveis e adaptados não são, necessariamente, os mais produtivos. Um exemplo disso é que os as linhagens 6 (ATF 46B) e 9 (B 803), foram classificadas entre as mais estáveis, mas estiveram abaixo da média em quase todos os ambientes. Portanto é recomendado que este método seja usado em conjunto com outros métodos que possuam correlação positiva com produtividade, como no caso Lin \& Binns ou Annicchiarico.
As linhagens 3 (9929020), 12 (CMSXS 230B) e 13 (N 95B) são linhagens tolerantes à seca e estáveis, tanto nos ambientes favoráveis quanto desfavoráveis, além de responsivas à melhoria do ambiente. As linhagens 11 (BR 008B), 23 (Tx 2908) e 18 (Tx 2737) apresentaram alta produtividade e estabilidade intermediária, sendo as duas primeiras mais estáveis nos ambientes favoráveis e a última nos ambientes mais desfavoráveis. Estas seis linhagens são candidatas promissoras para produção de híbridos de sorgo e deverão entrar em ensaios de estimativas de capacidade combinatória para tolerância à seca.

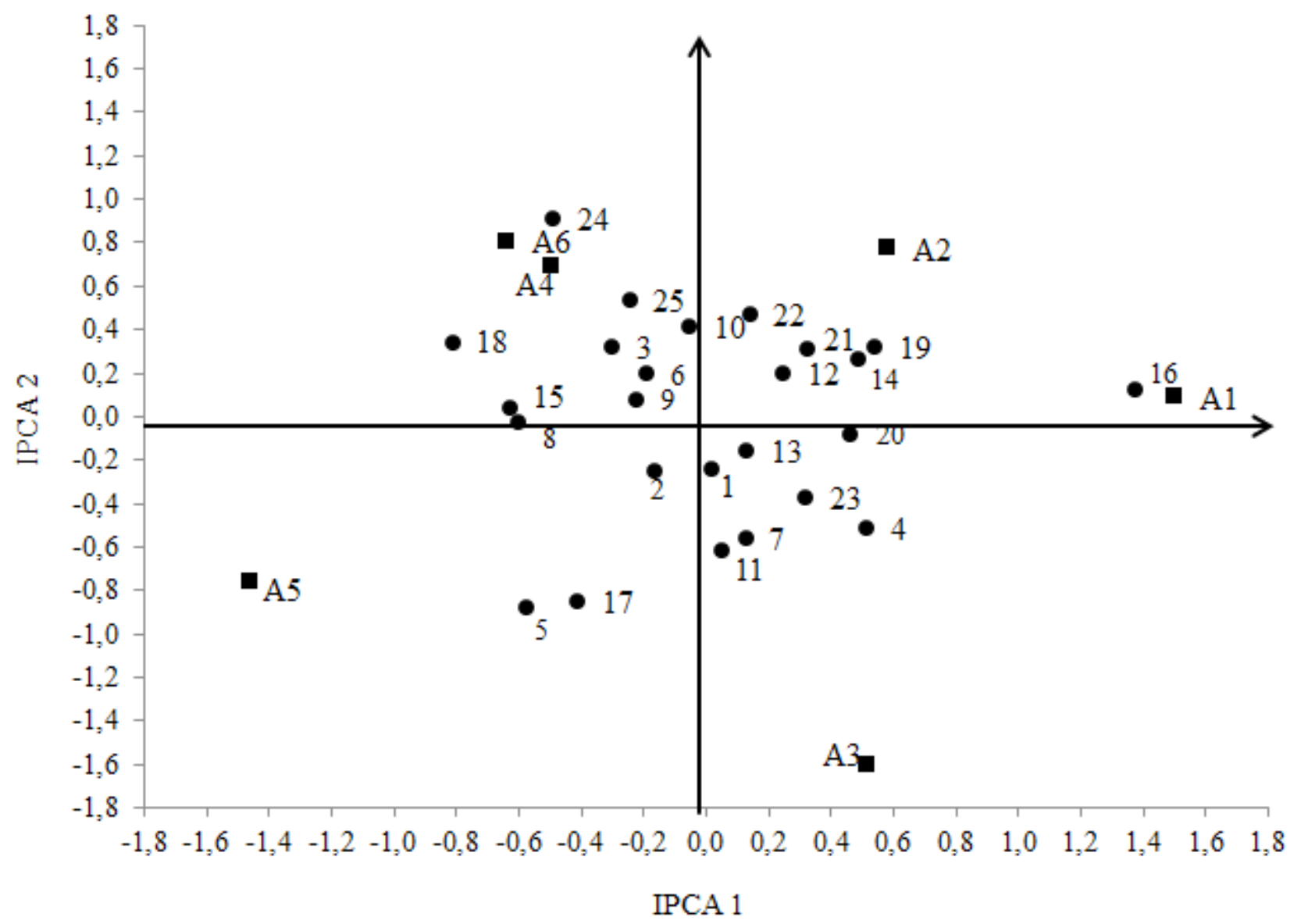

FIGURA 3. Biplot AMMI2 com os dois primeiros componentes principais de interação (IPCA1 e IPCA2), para dados de produtividade de grãos $\left(\mathrm{t} \mathrm{ha}^{-1}\right)$ de 25 linhagens de sorgo em seis ambientes. Códigos das linhagens de acordo com Tabela 2. Ambientes A1 (2006 SE), A2 (2006 CE), A3 (2007 SE), A4 (2007 CE), A5 (2008 SE) e A6 (2008 CE). 


\section{Conclusões}

A interação linhagens $\mathrm{x}$ anos foi mais pronunciada do que a interação linhagens x regimes hídricos, devendo-se aumentar o número de anos nas avaliações para tolerância a seca em sorgo.

As linhagens 9929020, CMSXS 230B e N 95B foram tolerantes à seca, estáveis e responsivas à melhoria do ambiente.

As linhagens BR 008B, Tx 2737 e Tx 2908 produziram bem na maioria dos ambientes e possuem estabilidade intermediária. Sendo as duas primeiras mais tolerantes à seca e a terceira de tolerância intermediaria.

As linhagens Tx 2862, Tx 2907 e SC 283 foram as menos estáveis em todos os ambientes, tanto favoráveis quanto desfavoráveis.

O método AMMI deve ser usado em conjunto com outro método de estabilidade com correlação positiva com produtividade, como Lin \& Binns ou Annicchiarico.

\section{Agradecimentos}

À Embrapa Milho e Sorgo, FAPEMIG e ao Fundo de Desenvolvimento Científico do Banco do Nordeste do Brasil (BNB), pelo apoio financeiro na realização e divulgação dos resultados.

\section{Referências}

ADUGNA, A. Assessment of yield stability in sorghum using univariate and multivariate statistical approaches. Hereditas, v.145, p. 2837, 2008.

ALBUQUERQUE, C. J. B.; VON PINHO; R.G.; RODRIGUES, J.A.S.; BRANT, R.S.;
MENDES; M.C. Espaçamento e densidade de semeadura para linhagens de sorgo granífero no semiárido. Bragantia, Campinas, v. 70, p. 278$285,2011$.

ALMEIDA FILHO; J. E; TARDIN, F. D; SOUZA, S. A.; GODINHO; V. P.; CARDOSO, M.

J. Desempenho agronômico e estabilidade fenotípica de híbridos de sorgo granífero. Revista Brasileira de Milho e Sorgo, Sete Lagoas, v. 9, p. 51-64, 2010.

ANNICCHIARICO, P. Cultivar adaptation and recomendation from alfafa trials in Northern Italy. Journal of Genetics and Breeding, v. 46, n. 1, p. 269-278, 1992.

ALVES, V.M.C.; VASCONCELLOS, C.A.; FREIRE, F.M.; PITTA, G.V.E.; FRANÇA, G.E. Sorgo. In RIBEIRO, A.C.; GUIMARÃES, P.T.G.; ALVAREZ V,V.H. (Ed). Recomendações para o uso de corretivos e fertilizantes em Minas Gerais, $5^{\text {a }}$ aproximação. Viçosa: CFSEMG, 1999. Cap. 18, p.325-327.

CHALAWADI, J. Heterosis and combining ability for grain yield and downy mildew resistance in kharif sorghum (Sorghum bicolor (L.) Moench). Dissertação de mestrado, Dharwad. 2007. 66p.

CONAB - Companhia Nacional de Abastecimento. Acompanhamento de safra brasileira: grãos, décimo segundo levantamento, setembro 2013 / Companhia Nacional de Abastecimento. - Brasília: Conab, 2013.

CORNELIUS, P.L.; SEYEDSADR, M.; CROSSA, J. Using the shifted multiplicative moldel to search for "separability" in crop cultivar trials. Theoretical and Applied Genetics, Stuttgart, v.84, n.1/2, p.161-172, June, 1992.

CRUZ, C.D.; CARNEIRO, P.C.S; REGAZZI, 
A.J. Modelos biométricos aplicados ao melhoramento genético. v.2, 3.ed. Viçosa: Editora UFV, 2014. 668P.

DUARTE, J.B.; VENCOVSKY, R. Interação genótipos $\mathrm{x}$ ambientes: uma introdução à análise AMMI. Ribeirão Preto: Sociedade Brasileira de Genética, 1999. 60p. (Série Monografias, 9)

FERREIRA, D. F. Software: Programa estabilidade. Disponível em: $\quad<$ http://www.dex.ufla. br/ danielff/softwares.htm>. Acesso em 01 de janeiro de 2014.

KÖEPPEN, W. Climatologia: con un Estudio de los Climas de la Tierra. México: Fondo de Cultura Econômica, 1948. 478 p.

LIMA, N. R. C. B. Disponibilidade de água e desenvolvimento de plantas de sorgo (Sorghum bicolor (L.) Moench.) e braquiária (Brachiaria Brizantha (A. Rich) stapf. cv Marandu) consorciadas. 2011. Dissertação (Mestrado em Ciência Animal e Pastagens). Universidade de São Paulo, Escola Superior de Agricultura Luiz de Queiroz, Piracicaba, 2011.

LIN, C. S.; BINNS, M. R. A superiority measure of cultivar performance for cultivar $\mathrm{x}$ location data. Canadian Journal of Plant Science, v. 68, n. 3, p. 193-198, 1988.

MAGAlhÃES, P. C.; DURÃES, F. O. M.; RODRIGUES, J. A. S. Fisiologia da Planta de Sorgo. Sete Lagoas: EMBRAPA Milho e Sorgo, 2003. 4 p. (Comunicado técnico $n^{\circ} 86$ ). OLIVEIRA, J. S.; FERREIRA, R.P.; CRUZ, C. D.; PERREIRA, A. V.; BOTREL, M. A.; VON PINTO, R.G.; RODRIGUES, J. A. S.; LOPES, F.C.F.; MIRANDA, J. E. C. Adaptabilidade e estabilidade em linhagens de sorgo. Revista Brasileira de Zootecnia, v. 31, p.883- 889,
2002.

RAMALHO, M. A. P.; ABREU, A.F.B.; SANTOS, J.B.; NUNES, J.A. Aplicação da genética quantitativa no melhoramento de plantas autógamas. Lavras: UFLA, 2012. 522p.

SILVA, A.G., BARROS, A.S.; SILVA, L.H.C.P.; MORÃES, E.B.; PIRES, R.; TEIXEIRA, I.R. Avaliação de linhagens de sorgo granífero na safrinha no sudoeste do Estado de Goiás. Pesquisa Agropecuária Tropical, v.39, p.168174, 2009.

SCHAFFERT, R. E.; ALBUQUERQUE, P. E. P.; DUARTE, J. O.; GARCIA, J. C.; GOMIDE, R. L.; GUIMARAES, C. T.; MAGALHAES, P. C.; MAGALHAES, J. V.; QUEIROZ, V. A. V. Phenotyping sorghum for adaptation to drought. In: MONNEVEUX, P.; RIBAUT, J.-M. (Ed.). Drought phenotyping in crops: from theory to practice. México, DF: CGIAR: CIMMYT, 2011. pt. 2, p. 287-299.

TARDIN, F. D.; MENEZES, C.B.; RODRIGUES, J. A. S.; COELHO, R. R. Linhagens. In: RODRIGUES, J. A. S. (Ed.). Cultivo do sorgo. 8. ed. Sete Lagoas: Embrapa Milho e Sorgo, 2012. (Embrapa Milho e Sorgo. Sistema de produção, 2).

TARDIN, F. D.; ALMEIDA FILHO, J. E. de; OLIVEIRA, C. M. de; LEITE, C. E. do P.; MENEZES, C. B. de; MAGALHAES, P. C.; RODRIGUES, J. A. S.; SCHAFFERT, R. E. Avaliação agronômica de híbridos de sorgo granífero cultivados sob irrigação e estresse hídrico. Revista Brasileira de Milho e Sorgo, Sete Lagoas, v. 12, n. 2, p. 102-117, 2013.

ZOBEL, R.W.; WRIGHT, M.J.; GAUCH, H.G. Statistical analysis of a yield trial. Agronomy Journal , v.80, p.388-393, 1988. 